\title{
Exploring the Pedagogical Potential of ICT Mediation for Promoting Students' Engagement: A Social Constructivist Perspective
}

\author{
Kalpana Kharade, Rupal Thakkar \\ College of Education, India
}

\begin{abstract}
Despite frequent attempts to address educational changes and the roles of ICT in effecting changes in student learning, few have acknowledged that effective use of ICT needs to be embedded in a larger process of instructional change. One possible direction is to frame ICT implementation as a dynamic process in which the benefits of ICT on student learning is mediated by pedagogical factors in a school setting. This study examines the perceptions of school students from secondary level about the usefulness of ICT mediation in fostering their engagement in language learning. For this a collaborative research project was designed and implemented in 3 secondary schools in the city of Mumbai, India. The team of the researchers comprising of 2 English method masters and 12 preservice English language teachers had designed a 2 stage module for this project. The first stage dealt with the pre-service teachers' level, while the second stage was related to the students' level. The project attempted to bring together the selected Schools' students and pre-service English language teachers in an ICT mediated learning environment and create learning situations, which sees the technology as a means of enhancing oral and written communication between students and teachers as well as among themselves. The scope of this paper is limited to the experiences of the students about ICT mediated collaborative language learning. The study sought to answer the following research questions: 1. What according to the students is the perceived usefulness of ICT mediated collaborative language learning? 2. In what way has the ICT mediation facilitated the promotion of students' engagement in collaborative language learning? Based on the qualitative analysis of the interview transcripts of the students and reflections of the pre-service teachers the researchers have come to the conclusions that the students found ICT mediation very useful in collaborative learning a language and promoting their procedural engagement in the learning process.
\end{abstract}

\section{Introduction}

The present global scenario emphasizes the 21st century skills to be developed among the learners, such as collaboration, learning how to learn, and knowledge construction, and requires changes in the academic culture of the educational institutions [11]. have rightly pointed out that, what the community accomplishes will be greater than the sum of individual contributions and part of broader cultural efforts. Hence it is high time that the teachers in Indian context adopt constructivism as their philosophy guiding their all instructional activities.

The term constructivist refers to a set of learning theories as an epistemological alternative to objectivist theories of knowledge [12]. Constructivist epistemology rejects the notion of knowledge transmission and emphasizes the active role of learners who construct their own knowledge by connecting their past experiences and knowledge with new ideas and concepts [5]. The constructivist principle gives rise to such learning approaches as learner-centered learning that place an emphasis on linking learning to learners' experiences and accepting multiple perspectives and there by promoting their active engagement in the process of learning [14]. In recent years, there has been enormous interest in using ICT for enhancing students' learning all over the world.

With this emerging technology in the 21st century, the implication of constructivist theory is often supported by the use of modern ICT tools. ICT is believed to support constructivist learning[6]because of its capability to provide learning environments for collaboration and social interaction, in which learners construct knowledge in the target language on their own "by engaging in meaningful activities. Contemporary pedagogical theories suggest that collaborative learning which is based on the constructivist paradigm is the most effective means of facilitating teaching and learning in digital environments [10].

Social constructivism is gaining foothold in school education around the world because teaching and learning can now easily be undertaken as a social and community activity thereby propagating collective learning (social) along with individual (cognitive) with the help of traditional email/chatting and modern wikis, blogs, vblogs, RSS feeds etc. [8].

But in Indian schools this most needed ICT application to education in general and language instruction in particular is still very limited. The empirical evidences point at the main reason for this issue, that, Education is a very socially oriented activity and in Indian Educational culture characterized by pedagogical hierarchy, it has traditionally been associated with strong teachers having high degrees of personal contact with and 
strong influence on the learners. The use of ICT in education lends itself to more student-centered learning settings and often this creates some tensions for some teachers and students [7].

Many researches in the area of ICT enhanced constructivist learning are conducted in Science and Mathematics learning context. These studies examine interactional constructivist moves with the nature of idea refinement, and developing better conceptions of an idea. But research in ICT enhanced constructivist language learning seems to lag behind. Existing studies on constructivism in ICT mediated language learning are mainly concerned about children's literacy development or collaborative writing [15].

Thus, we found two problems that led to the starting point of this study. The first problem involves a mismatch between current English language instructional practices in the L1 context in India and the evolving need to prepare learners in the 21st century. The second problem stems from the lack of empirical research related to ICT Mediation in constructivist language learning.

\section{Theoretical Perspective of the Study}

We consider social constructivism as a theoretical perspectives as background framework to study the effectiveness of ICT mediation in meaningful learning of language among the learners and promoting engagement among them. Next we give background of the perspective that provides the theoretical foundation for our research.

The constructivist pedagogical strategies help to create Learning environments promoting active engagement of the learners and provide contentrelevant experiences by utilizing ICTs and resources to support unique learning goals and knowledge construction [16].

The strengths of constructivism lie in its emphasis on learning as a process of personal understanding and the development of meaning where learning is viewed as the construction of meaning rather than as the memorization of facts. Learning approaches using contemporary ICTs provide many opportunities for constructivist learning through their student centered environments based on their context [9]. The current trend in e-Learning is to provide cognitive tools, which can be adapted for intellectual partnerships among teachers and students and facilitate critical thinking and higher-order learn [16].

Social constructivism emphasizes collectiveLearning where the role of teachers, parents, peers and other community members in helping learners becomes prominent. Social constructivists emphasize that learning is active, contextual and social; therefore the best method is 'group-learning' where teacher is a facilitator and guide[13]. Social constructivists explain the technology-adoption as a process of involving social groups into the innovation process where learning takes place on the learners' experiences, knowledge, habits and preferences [1].
In contrast to traditional classrooms where teachers used a linear model and one-way communication, the modern learning is becoming more student-centric, nonlinear and learner-directed [2]. Social constructivists also believe that culture too influences the design and development of the learning models[14]. It is therefore very essential to move ICT beyond learning management systems and engage students in using it as a resource for their selfgoverned, problem-based and collaborative activities like using social software [3].

Besides, in recent years, it has been recognized that ICT mediation is not merely another medium for the transmission of knowledge but that it changes the relationship between the teacher or trainer and learner. It requires new skills, competencies and attitudes amongst those curriculum planners, educational leaders, teachers and trainers who are going to design and develop materials and support learners online as well as off line [4]. Thus, it is necessary to study the impact of ICT mediation in creating social constructivist learning environment through multiple perspectives. It is therefore the researchers collaborated with pre-service language teachers and the learners. In order to make the ICT mediation along with the social constructivist learning principle work, we must understand how such a learning mode would be used, especially concerning the ways in which teachers go about exploring the mode. Additionally, we need research that informs us about whether ICT can really mediate collaborative language learning and there by promote students' engagement in the process of learning. In sum, this study is hoped to shed light on how the ICT mediation could be used in real-life English language classrooms by primarily sorting out the relationships among learners, teachers, and the ICT within the L1 context. Hence the aim of the study was to explore the possibility of using ICT mediation as a pedagogical tool in promoting students' engagement in language learning and studying their perceived usefulness of ICT mediation in language learning.

To attain the above mentioned aims the following research questions were posed:

1. What according to the students is the perceived usefulness of ICT mediated collaborative language learning?

2. In what way has the ICT mediation facilitated the promotion of students' engagement in collaborative language learning?

\section{The Study}

\subsection{Method}

Qualitative approaches to classroom research are appropriate because they employ a variety of methods that can help clarify phenomena, add valuable contextual information, emphasize discovery (rather 
than verification), and describe what is happening to study participants. In particular, case studies are well suited to in-depth examination of educational practice. The study described here was qualitative in nature and employed a case study methodology. It took the form of teacher research, which we, like many educators value as a form of systematic, intentional inquiry about classroom dynamics.

\section{- Participants}

The participants of the study comprised of:

i. Two English method masters,

ii. Twelve pre-service teachers and

iii. 150 7th-std students from selected three schools.

\section{- Setting}

A week long project was applied after getting the academic support from the pioneering schools which adopted a policy of supporting ICT Mediated communication for different academic and administrative purposes.

Organizational framework was designed and applied last week of January 2011 in near by schools, which were chosen according to appropriateness of its technical Infrastructures and whole hearted cooperation of the staff. In the study, the twelve preservice teachers were divided into three groups. Each group of pre-service teachers was allotted one school. Each group was given the responsibility of one division of std 7 . Further, the students in the allotted class were divided into subgroups. These groups were made as per the activity selected by them. Each sub-group had one leader, two content managers and two technology managers. Each subgroup worked under the pre-service teachers who functioned as facilitators for their projects.

The project started with the idea of bringing together the selected Schools' students and pre-service English language teachers in an ICT mediated learning environment and create constructivist learning situations, which see the technology as a means of enhancing oral and written communication between students and teachers as well as among themselves. The study has gone beyond the traditional classroom activities because of intending to provide a ICT-supported collaborative learning environment and promoting their engagement in the same. Throughout the project, students improved their ability to investigate specific topics, analyze and synthesize the findings. In addition, students worked cooperatively in groups to attain academic as well as affective and social goals.

\section{- Project design}

The team of the researchers had designed a 2 stage module for this project. The first stage dealt with the pre-service teachers' level, while the second stage was related to the students' level. The module can be diagrammatically shown as follows-

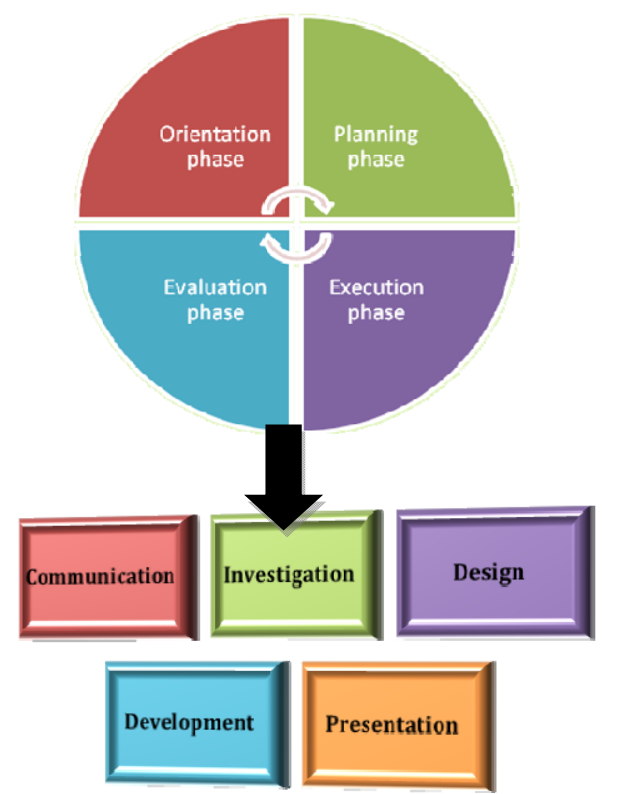

Figure 1. Teachers' and Students' level design

A. Teachers' level design:- At this level the design had the following objectives-

1. To design a training module for the preservice teachers for -

a. Developing understanding about theoretical background of engagement theory and its application in language learning,

b. Developing technological and pedagogical knowledge for transacting the selected language content in ICT mediated learning environment.

2. To develop instructional materials for promoting std 7 students engagement in language learning in ICT mediated language learning environment.

This level design had the following phases:

1. Orientation phase: At this phase the pre-service teachers were oriented to the concept of engagement theory, need for ICT mediation for enhancing learning and need for promoting engagement among students for language learning.

2. Planning phase: The team of pre-service teachers under the guidance of English method masters selected 3 areas of language learning namely- writing composition, poetry comprehension and creative writing. School group 1 of pre-service teachers selected "My favorite place" as a topic for written expression. But the forms of written expressions were beyond the traditional writing of compositions. The sub- groups of the students in the class chose to write issue based news paper articles, compose poetry depicting the glory of the place and TV narratives. All these products were developed with ICT applications. The second school group decided to work on in depth poetry comprehension. The sub-groups were expected to develop concept webs, literary analysis and effective recitations of the given poems. The third 
school group worked on creative story writing, converting the plots into scripts and make ICT supported animated presentations of the scripts in the form of E-comics. Here the English method masters along with the pre-service teachers planned the daily sessions, instructional materials, rubrics and concept webs.

3. Execution phase: A detail schedule of 4-5 days comprising of 5 stages was chalked. These stages included- communication, investigation, design, development and presentation. The detailed explanation of these stages is given in the second phase. Evaluation- The effectiveness of the project was studied in terms of students perceptions about the ICT mediated constructivist learning environment in promoting their engagement in language learning. For this groups of students were interviewed and the collected data was analyzed qualitatively.

B. Design at the students' level:- At this level the design had the following objectives-

1. To develop an instructional design for promoting std 7th students engagement in learning language in ICT mediated environment,

2. To facilitate the students language learning in ICT mediated learning environment bya. Fostering inter group and whole class collaboration and communication;

b. Encouraging them to investigate with respect to their selected language tasks;

c. Facilitating students' designing, developing and presenting stages of language learning tasks by providing appropriate technological and pedagogical support.

3. To study the students' perceptions about usefulness of ICT mediation in constructivist language learning with respect to -

a. Making learning effective,

b. Developing interest in language learning,

c. Providing opportunities for variety of creative expressions enhanced through ICT mediation,

d. Enabling them to make creative presentations

e. Fostering cooperation in group work,

f. promoting engagement in the process of learning

There were 5 stages students entered throughout the project; communication, investigation, design, development, and presentation.

Following is the brief description of students' engagement across these stages:

- Communication: Communication was interconnected in each phase. Students contacted with their sub-group peers by using ICT mediated communication tools like emails, chats etc. They introduced themselves and tried to get to know other group members. During this phase logo, color combinations, titles, characters and jingles etc were discussed. Discussions were noted by the leader or by the content managers of each sub-group and documented on their files.

- Investigation: Sub-groups started their investigations and it continued for two days. They communicated with each other via e-mail and Microsoft Net meeting chat tools. They shared the findings as texts, images, and animations and shared them within sub-group. The individual and group working and communication activities were facilitated by the facilitators. Needed sources were supplied by facilitators to students when they were necessary.

- Design: Findings were documented and distributed to group members. Group members decided on the design template and design layouts within PowerPoint program and collected related data afterward.

- Development: It lasted two days. Students developed their PowerPoint presentations. They combined the slides of the sub-groups and created one unique product, which belonged to the whole group at the end of the two day period. Final products were reviewed and revised by the facilitators. The English method masters also gave their inputs in the final versions of the products.

- Presentation: Students presented their products in a communicative manner at a common session. The representatives of each group were asked to make the presentation in front of the class.

The ICT mediation in this study was attained as follows:

\section{Working Areas:}

- Students and facilitators worked collaboratively at allotted Schools' audio visual rooms.

- The technical facilities of all three schools were as follows: Each school has a well equipped Audio Visual room with the sitting capacity of around 50 students.

- Communication Types (Synchronous/ asynchronous). The communication process had both synchronous and asynchronous characteristics.

- We used Microsoft Net meeting program in the project as a synchronous communication tool. In asynchronous communication, the participants are not on-line at one and the same time, as in the case of correspondence by letter or fax. Groups SMS and emails as asynchronous communication tools were used in this study.

\section{- Communication Modes}

In the project, one-to one and one-to-many modes were used. As one-to-one communication mode, email tools and Microsoft Net meeting or telephonic conversations were used. E-groups were also formed to enable one-to-many communication mode.

- Media 
Media used in the project are presentation tools, email, Internet, search engines, CDs. and voice chat rooms.

\section{Results and Discussion}

To study the effectiveness of the project the students' perceptions with respect to usefulness of ICT mediation in collaborative language learning and students' procedural engagement in the process of learning and tasks completions were collected with the help of focused group interview. The pre-service teachers were also asked to write their daily reflections in their reflection logs. To improve the validity of the results and to minimize the subjectivity of the researchers' interpretation, data were collected from multiple sources.

Based on the qualitative analysis of the interview transcripts and reflections the researchers have tried to answer the research questions.

\subsection{Research Question 1}

The students found the ICT mediated constructivist learning environment useful for language learning which is evident from the following aspects. Creating interest in learning: All the students liked the ICT mediated projects of language learning very much. They found the assigned tasks very interesting. This must have happened because they found the tasks novel. . It is seen from their following responses-

"this approach is any time better as it helps us to be more creative and we are actively participating during class rather than listening to the teachers silently ,which becomes boring”,

The following remark is even very encouraging-

"The use of technology made learning more interesting, and every morning we would awake with the want to go to school imagining "WHAT WE ARE GOING TO LEARN TODAY \& HOW”.

Another reason for finding the activities interesting can be the connection with real life. One student said in this context

"I always thought that my village should a tourist spot where many people should come to enjoy, but never thought that I can write a news paper article on it.”

The freedom of choosing the mode of expression may also have contributed to the increase in interest in learning which is evident from the following response-

"I could choose to do TV narrative which I always found to be fascinating." Some students also attributed their interest to creative endeavor. See the following statement-

"Some of us wrote poem on the given topic you know! And what an idea to mix sounds and pictures! Simply great”

Relating and catering to the real audiences must have also increased their interest in the project. See the following statement- "So nice to present in front of real people and not to imagine writing letters to imaginary relatives or friends who will never read our letters or essays.

Making difference in learning: According to 93\% students these projects were very helpful in terms of learning which is evident from some of their responses-

"Learning was not at all a burden, in fact it was a fun to write about our favorite place."

"With the help of concept webs I understood the poem very much in depth", I never thought I can write a story on my own" As we made our poem we looked for new and better words. While writing we were refining the matter over a number of times, we really want to do the best you see!”

Better acquisition of learning materials: According to $97 \%$ students the visuals, graphics have helped them to better understand the tasks and distributed instructional materials.

Following responses confirm this claim "The concept web and the pictures made the understanding easier you know?", The pictures, the sounds made the understanding of the poems so easy", "the story map makes so easy to compose the story, I can't believe that"'” I could never think about writing a news paper article, "the pictures, sound made the analysis of the poem so effective" etc...

Help in test preparation: The $88 \%$ students felt that if the teachers will teach like in these projects they will easily remember the things and would not be anxious about writing stories, essays in the answer papers. They would also not get scared of unseen poems in the exam. Following are some of the statements of the students confirming the findings- "I think, if we learn poems like this, I will easily answer the questions of unseen poems, "writing the conversations will not be difficult at all." "Descriptive essays will not be difficult if we learn this way."

Potential negative outcomes: In spite of the unanimous "yes" in favor of the ICT mediation in language learning 92\% students found such projects to be very time consuming. They also felt that it would not be practical to always conduct classes like this. Following are some of their opinions- 
“They are good, but always? Don't know!”, “I think our parents may complain”, Good but, we have to spend so many hours for this" all may not have computers at home”,

"Principal may not permit to spend so much time in the A.V. room." "When we will learn other subjects?"

These statements do indicate at the negative outcomes of ICT mediation, but here the fundamental questions arise "How long are we really going to continue to teach English in such prescriptive and exam oriented way?

"When are we going to provide a learner an autonomy and creative freedom by facilitating their learning?

\subsection{Research Question 2}

We had operationalized student's engagement as taking initiative in accepting the task, exerting efforts to plan the task, solving problems in the completion of the tasks and persistently completing it. The following statements do reflect the students' engagement in the learning tasks:

"The preparation of presentation was a Herculean task, since it was the 1st time we were made to think differently and move to novel ideas even they were difficult to bring in to reality”.

"We must admit that converting our ideas into different forms was difficult, whether poetry, newspaper article or interview. It took us time to rearrange our line of thoughts but as we progressed, more ideas came by, as well as the technique got simpler”.

"It got us involved day and night to search and replace the existing words with more effective words \& pictures and even sounds."

"Thinking in a different way was challenging but as the teachers guided us and we group members put our heads together we found it easy and interesting”.

“Applying appropriate backgrounds and animations was a tedious task, but we must admit we could finally make it.”

Their further statements do support that ICT mediation has helped in accelerated their engagement. We are giving their statements according to the 5 stages of their actions:

- Communication - "We could talk to each other and with our group teachers over phone, send mails of our group work and make changes immediately"

- Investigation - "We could find lovely pictures, sounds about our topics. We could get good material on our favorite place "I do not think we could have done so well without computers and internet."

- Design - "We could think, rethink and make changes in our project the way we wanted. It ." is very easy to do with computers, manually it would have been simply impossible I feel”!

- Development - "Our article was just like a newspaper" The poetry presentation was like a mini film"

- Presentation - "We felt so great to handle ppt and present our work in front of our class friends." "We were proud to show our work and tell about it to all."

The above discussion help us to conclude, perhaps in a limited way that, ICT mediation does have contributed to the promotion of students' engagement in language learning and it does have enhanced the language learning of the students by providing novelty of activities, establishing connections with their lives, ensuring creativity and freedom of choice for expressions.

\section{Conclusions}

This article discussed an exploratory study in which the possibility of using ICT mediation as a pedagogical tool for creating constructivist language learning environment and promoting students engagement in collaborative language learning was studied.

It was found that, ICT mediated constructivist learning environment provided the participants with a good opportunity for collaborative language learning (Research Question 1). The students who participated in the study were in favor of the use of ICT mediation tools. The students had a strong desire to use ICT not only while the research study was conducted but also after the study was completed. The ICT mediation also promoted students' procedural engagement in collaborative language learning (Research Question 2).

This supports the findings of previous studies that students' learning experiences are improved with the use of ICT mediated collaboration [2].

The findings from this study may not be generalized beyond this study's population because of the small sample size and the fact that the students were volunteers to participate in the study. However, the study does provide suggestions on how students' engagement in language learning can be promoted.

We also hope that this research will be able to shed some light on attitudinal issues related to ICT application in creating constructivist learning environment and promote students' engagement in learning process.

We also see two main directions for future research. First, the in-service teachers could be made the part of collaborative team along with teacher educators, pre-service teachers. Second, the 
perceptions of pre-service and in-service teachers as a collaborative team about ICT mediated social constructivist approach to language learning and partnership between the schools and colleges of education in improving quality of language instruction could be studied. Last but not least, the sample size could be enlarged so that patterns might be observed.

\section{References}

[1] Bondarouk T.V., (2006). Action-oriented group learning in the implementation of information technologies: results from three case studies. Eur. J. Info. Syst., 15: 42-53. Retrieved April 19, 211, from http://www.palgrave- journals.com/ejis/

[2] Cagiltay NE, Yildirim S, Aksu M (2006). Students' Preferences on Web-Based Instruction: linear or non-linear. J. Edu. Technol. Soc., 9(3):122136. Retrieved July 13, 2011, from http://www.ask4research.info/.

[3] Dalsgaard C (2006). Social software: E-Learning beyond learning management systems. Eur. J. Open, Distance and E-Learning.Retrieved June 11, 2011, from http://www.eurodl.org/.

[4]Gray DE, Ryan M, Coulon A (2003). The Training of Teachers and Trainers: Innovative Practices, Skills and Competencies in the use of eLearning. Eur. J. Open, Distance E-Learn. Retrieved April 42, 2011, from http://www.eurodl.org/.

[5]Heibert, E. H. (1991). Literacy for a diverse society: perspectives, practices, and policies New York: Teachers College Press, Teachers College, Columbia University.

[6]Judson, E. (2006). How teachers integrate technology and their beliefs about learning: Is there a connection. Journal of Technology and Teacher Education, 14 (3), 581597.

[7] Kharade K. R., Thakkar R. A.( 2011). Promoting ICT enhanced Constructivist Teaching Practices among Pre-service Teachers: a case Study International journal of Scientific research and Publication IJSRP .Retrieved on December 23, 2011 from http://www.ijsrp.org/research-paper-publishingjan-2012.html

[8]Klamma R, Chatti MA, Duval E, Hummel H, Hvannberg EH, Kravcik M, Law E, Naeve A, Scott P (2007). Social Software for Life-long Learning. J. Educ. Technol. Soc., 10(3): 72-83. Retrieved June 26, 2011, from http://www.ask4research.info/.

[9]Oliver,( 2002).The role of ICT in higher education for the 21st century: ICT as a change agent for education. Retrieved April 14, 2011 from http://elrond.scam.ecu.edu.au/oliver/2002/he21.pdf (2008).

[10]Phillips P, Wells J, Ice P, Curtis R, Kennedy R (2008). A Case Study of the Relationship Between Socio-Epistemological Teaching Orientations and Instructor Perceptions of Pedagogy in Online Environments. Elect. J. Integ. Technol. Educ., 6: 3-27. Retrieved May 10, 211, from http://ejite.isu.edu/ 6 (1).

[11]Scardamalia, M., \& Bereiter, C. (2003). Knowledge Building. In Encyclopedia of Education, Second Edition. New York: Macmillan Reference, USA.

[12] Swan, K. (2005). A Constructivist Model for Thinking About Learning Online. Needham,MA: Sloan-C.Thamra

[13] Tinio VL (2002). ICT in education. Presented by UNDP for the benefit of participants to the World Summit on the Information Society. UNDP's regional project, the Asia-Pacific Development Information Program (APDIP), in association with the secretariat of the Association ofPhillips (Eds), Beyond the comfort zone: Proceedings of the 21st ASCILITE Conference, pp. 20-35. Perth, 5-8 December. Retrieved June 10, 2011, from http://www.ascilite.org.au/conferences/perth04/procs/ valckekeynote.html.

[14]Ward T, Monaghan K, Villing R (2006). MyVLE: A case study in building a universal telematic education environment for a small university. Eur. J. Open, Distance E-learn. Retrieved April 16, 2011, from http://www.eurodl.org/.

[15] Wells, G. (1999). Dialogic inquiry: Toward a socio cultural practice and theory of education. New York: Cambridge University Press.

[16] Young LD (2003). Bridging Theory and Practice: Developing Guidelines to Facilitate the Design of Computer-based Learning Environments. Canadian J. Learn. Techno, 29(3), Fall/Autumn. Retrieved May 24, 2011, from http://www.cjlt.ca/.

\section{Acknowledgement}

The authors are grateful to the twelve pre-service teachers who collaborated in this exploratory study and the $7^{\text {th }}$ std students who participated in this project. 